\title{
Diversity and specificity of sap-feeding herbivores and their parasitoids on Australian fig trees
}

Article

Accepted Version

Fromont, C., DeGabriel, J. L., Riegler, M. and Cook, J. M. (2017) Diversity and specificity of sap-feeding herbivores and their parasitoids on Australian fig trees. Insect Conservation and Diversity, 10 (2). pp. 107-119. ISSN 1752-4598 doi: https://doi.org/10.1111/icad.12202 Available at https://centaur.reading.ac.uk/68700/

It is advisable to refer to the publisher's version if you intend to cite from the work. See Guidance on citing.

Published version at: http://dx.doi.org/10.111//icad.12202

To link to this article DOI: http://dx.doi.org/10.1111/icad.12202

Publisher: Wiley

All outputs in CentAUR are protected by Intellectual Property Rights law, including copyright law. Copyright and IPR is retained by the creators or other copyright holders. Terms and conditions for use of this material are defined in the End User Agreement.

www.reading.ac.uk/centaur 
Central Archive at the University of Reading

Reading's research outputs online 
1 Diversity and host specificity of Mycopsylla species (Hemiptera: Homotomidae) and their

2 Psyllaephagus parasitoids (Hymenoptera: Encyrtidae) on figs (Ficus).

3

4 Caroline Fromont ${ }^{1 *}$, Jane L. DeGabriel ${ }^{1}$, Markus Riegler ${ }^{1}$, James M. Cook ${ }^{1,2}$

$5 \quad{ }^{1}$ Hawkesbury Institute for the Environment, Western Sydney University, Locked Bag 1797, Penrith, NSW 2751, Australia

${ }^{2}$ School of Biological Sciences, University of Reading, Reading RG6 6AS, UK.

9

$10 *$ Corresponding author: Caroline Fromont, email: c.fromont@westernsydney.edu.au,

11 caroline.fromont.cf@gmail.com

12

13

Running title: Fig homotomids and parasitoids

16

Keywords: Phylogeny, parasitoid, cryptic species, morphology, species specificity, psyllid

17

18

19

20

21 
1. The ecology, diversity and parasitoid complex of plant-sap feeding insects of the family Homotomidae (Hemiptera: Psylloidea) specialised on fig trees (Ficus) have so far received little research attention. However, they are ecologically important, as occasional outbreaks of the homotomid Mycopsylla fici may cause complete defoliation of its host plant, the Moreton Bay fig (Ficus macrophylla). Mycopsylla proxima, the only other species reported from Australia, feeds on $F$. rubiginosa without any recorded outbreaks.

2. We searched for homotomids and their parasitoids on eight Ficus species on the east coast of Australia, Lord Howe Island (LHI) and in Auckland, New Zealand, and detected them on three Ficus species. Using mitochondrial and nuclear DNA sequences, we delimited three Mycopsylla species, including a putative new species on $F$. watkinsiana. We also characterised six (including one previously described) parasitoid species of the genus Psyllaephagus (Hymenoptera: Encyrtidae) based on congruent morphological characters and molecular data.

3. Each of the homotomid species was highly host-specific to a single fig species, while parasitoid species varied in host-specificity: three host-specific to $M$. fici and three hostgeneralists. Geographic distribution varied among parasitoid species; e.g. one host-specific species was found on both the mainland and LHI, but a second species only on LHI.

4. Our study revealed previously unrecognised diversity in fig homotomids and especially in their parasitoids. The herbivores and parasitoids showed contrasting patterns of host-specificity. Interestingly, $M$. fici, the only outbreak species, had the highest diversity of associated parasitoid species and was the only species with host-specific parasitoids. 
46

Any given insect species is typically involved in complex interactions with several other species, as part of a food web that characterises feeding interactions through sets of links between species (Pimm et al., 1991). For example, an insect herbivore acts both as a consumer of its host plant(s), and as a host for parasitoids or prey for predators. Correct assessment of host specificity and trophic links first requires accurate delimitation of the species (host plant, its herbivores and their parasitoid species) involved, which may be complicated by the existence of cryptic species. Furthermore, a crucial step in understanding food web structure is the study of the degree of specialisation, i.e. the number of host species, for each species involved. This is of importance for assessment of community dynamics (van Veen et al., 2006) and global species diversity (Mora et al., 2011), as well as for more applied purposes, such as biological control (Stiling \& Cornelissen, 2005).

Fig trees (Ficus, Moraceae) form a large plant genus (Frodin, 2004), comprising approximately 750 species worldwide, with the highest diversity ( $>500$ species) in Asia and Australasia (Rønsted et al., 2008). Fig trees may be keystone species (Terborgh, 1986) and Janzen (1979) noted that they support a large diversity of frugivores and other herbivores. Amongst the insects, various flies and beetles, as well as diverse fig wasp lineages, rely on fig fruit resources (Basset et al., 1997). Fig trees are intensively studied for their mutualistic interaction with tiny pollinator wasps (Hymenoptera: Agaonidae), with which they show high reciprocal partner specificity (Cruaud et al., 2012). Despite intense interest in fig - wasp symbiosis, far less research has been undertaken on other insect herbivores feeding on fig trees (Basset et al., 1997; Basset \& Novotny, 1999; Novotny et al., 2005). Fig trees are host plants for Mycopsylla spp., sap-sucking insects of the family Homotomidae (Hemiptera: Psylloidea). These homotomids are sometimes referred to as "fig psyllids", but they do not belong to the family Psyllidae and their diversity and ecology has been far less studied than other families of the Psylloidea superfamily. 
Mycopsylla spp. appear to feed only on Ficus and their nymphs produce a sticky covering on the lower surface of fig leaves, a 'lerp', under which they develop (Newman, 2004). The biology of Mycopsylla has been relatively little studied and their diversity and host relations are poorly understood. However, the ecological importance of Mycopsylla fici (Tryon) cannot be neglected, as it experiences occasional massive population outbreaks as observed in Sydney in 1996 (Newman, 2004) and on Lord Howe Island (LHI, volcanic remnant located $\sim 600 \mathrm{~km}$ off the east coast of Australia) in 2013/2014 (CF, JLD \& JMC, pers. obs.). Outbreaks may result in complete defoliation of its host plant, Ficus macrophylla (Nicholls, 1939; Newman, 2004), limiting the number of leaves and fruits available to support other animals that feed or shelter on the tree. More generally, several species of the superfamily Psylloidea are known for major outbreaks on various plant species that can result in significant damage to host plants and ecosystems (e.g. Bactericera cockerelli, Hill, 1947; Cardiaspina sp., Hall et al., 2015; Cardiaspina fiscella Gherlenda et al., 2016).

In Australia, Ficus species diversity is highest in north Queensland and the Northern Territory, but several species are also widespread in southern Queensland and coastal New South Wales, with diversity decreasing southwards. While most areas have several co-occurring fig species, only two Mycopsylla species, M. fici (Tryon) and M. proxima Froggatt, have been described in Australia, on Ficus macrophylla Desf. ex. Pers. (Moreton Bay fig) and Ficus rubiginosa Desf. ex.Vent. (Port Jackson fig), respectively (Froggatt, 1901; Hollis \& Broomfield, 1989). Mycopsylla fici is found on the two forms of its host F. macrophylla: f. macrophylla is native to wet forests in Eastern Australia, from the South Coast of New South Wales (NSW) to southern Queensland, while f. columnaris is endemic to LHI (Dixon, 2001). Outside their natural distribution, F. macrophylla trees have also been planted in numerous parks and gardens across Australia (e.g. in Melbourne and Perth), and overseas, e.g. in Auckland, New Zealand, since the $19^{\text {th }}$ century. Mycopsylla fici is also present in Auckland, where it was first recorded in 1995 (Bain, 2004). The distribution of F. rubiginosa, the host of $M$. proxima, overlaps the smaller range of F. macrophylla, and is continuous from near Eden in southern NSW to Cape York 
Peninsula in far north Queensland. In contrast to M. fici, M. proxima has not been reported as an outbreak species or as causing complete defoliation of its host. In addition to these two Australian species, three Mycopsylla species have been described from India (although Newman (2004) suggests that they are only a single species), one from Papua New Guinea, and three from New Caledonia, including one from the Loyalty Islands (Hollis \& Broomfield, 1989).

Nymphs of Psylloidea species are attacked by various parasitoid wasps and most of these belong to the genera Psyllaephagus Ashmead (Hymenoptera: Encyrtidae) and Tamarixia Mercet (Hymenoptera: Eulophidae) (Riek, 1962; LaSalle, 1994). Newman (2004) studied the basic biology of M. fici during a major outbreak in Sydney in the late 1990s and recorded the presence of Psyllaephagus wasps, noting two different size classes of females. These may have represented two different species, but this was not explored further. In fact, there have been no detailed descriptions of any parasitoid species attacking Mycopsylla species in Australia. Interestingly, one species (Psyllaephagus cornwallensis) attacking M. fici has been described from New Zealand, where the host tree and homotomid were introduced (Berry, 2007). It is not yet known if this parasitoid species is native to Australia, although this is highly likely. In Australia, the diversity and host specificity of psyllid parasitoids besides the ones feeding on Eucalyptus specialised psyllids (Riek, 1962) are not well described.

More extensive sampling is needed to assess the diversity and host specificity of Mycopsylla spp. and their associated parasitoids in eastern Australia. In this study, we focussed on a food web that comprises Australian Ficus species in the section Malvanthera, their homotomids (Mycopsylla spp.), and associated parasitoids (Psyllaephagus). We addressed three key questions: 1) Are homotomid and parasitoid diversity higher than previously described due to the existence of un-sampled or cryptic species? 2) How host-specific are fig homotomid and parasitoid species? 3) Do closely related parasitoid/homotomid species utilise the same, or closely related, homotomid/Ficus species? 


\section{Study species and insect sampling}

Multiple fig species are found on the eastern coast of Australia and we searched for homotomids on two dioecious species from the Ficus section Sycidium (Ficus coronata $(\mathrm{n}=30-40$ trees), Ficus fraseri $(\mathrm{n}=14))$ and six monoecious species from two Ficus sections - Malvanthera $(F$. macrophylla $(\mathrm{n}>100)$, F. rubiginosa $(\mathrm{n}>100)$, Ficus obliqua $(\mathrm{n}>60)$ and $F$. watkinsiana $(\mathrm{n}=40-$ 50) and Conosycea (Ficus microcarpa (n>100), Ficus benjamina (n>100)). In Australia, Mycopsylla spp. have previously only been recorded from the two malvantheran fig species, $F$. macrophylla and F. rubiginosa. Multiple collections were made between March 2013 and December 2014 to sample fig homotomids and parasitoids along the eastern coast of NSW and Queensland from Wollongong to Brisbane, as well as in Melbourne (Victoria), on LHI and in Auckland, New Zealand (Fig. 1 and Table S1 in Supporting Information).

Infested leaves were only found for three Ficus species. Leaves with lerps (solidified excretions by the nymphs forming a sticky protective covering, Newman, 2004) were collected from multiple branches of infested $F$. macrophylla, F. rubiginosa and $F$. watkinsiana trees and kept in Petri dishes at ambient room temperature $\left(\sim 20^{\circ} \mathrm{C}\right)$ until adult insects (homotomids and parasitoids) emerged. In addition, homotomid nymphs were collected directly from lerps soon after field sampling. Specimens were preserved in absolute ethanol and stored at $-18^{\circ} \mathrm{C}$ until DNA extraction. For the analysis, we then chose 36 homotomids (23 individuals from $F$. macrophylla, 11 from $F$. rubiginosa and 2 from $F$. watkinsiana) and 128 parasitoids (95 from homotomids on F. macrophylla, 31 from homotomids on $F$. rubiginosa and 2 individuals from homotomids on $F$. watkinsiana), representing the morphological, host and geographic diversity of the adult specimens collected (Fig. 1). However, only homotomid nymphs were collected from F. watkinsiana. 
We first grouped all homotomids and parasitoids into distinct morphotypes, with Psyllaephagus morphotypes based on the descriptions by Froggatt (1901) and Hollis and Bromfield (1989). In addition, we measured and assessed several parasitoid morphological traits, following Noyes \& Hanson (1996) and Berry (2007). Prior to molecular analysis, all parasitoids were photographed using a stereomicroscope and the INFINITY ANALYZE software (Lumenera corp., Ottawa, ON). Body and antenna lengths were measured for male and female parasitoids. Ovipositor sheath length was measured for females, and antennal morphology was recorded for males and females. We compared the measured traits (i.e. body length, sheath length:body length and antenna length:body length) between species, using a Kruskal-Wallis test with the Benjamini and Hochberg (1995) correction and multiple comparison of treatments as implemented in the R package ‘agricolae' (De Mendiburu, 2014; R Development Core Team, 2014).

\section{DNA extraction and sequencing}

DNA was extracted from the entire body of individual homotomids and parasitoids using a Chelex method (Walsh et al., 1991). Individuals were placed into $100 \mu \mathrm{L}$ homogenization solution ( $5 \%$ Chelex, $0.01 \%$ proteinase $\mathrm{K})$, crushed with a pestle, incubated at $56{ }^{\circ} \mathrm{C}$ for $35 \mathrm{~min}$ then at $96^{\circ} \mathrm{C}$ for $15 \mathrm{~min}$ and centrifuged for $5 \mathrm{~min}$ at $13,000 \mathrm{rpm}$.

We sequenced three homotomid gene fragments - mitochondrial Cytochrome Oxidase 1 (COI), and nuclear Histone 3 (Hist3) and Elongation Factor $1 \alpha($ EFl $\alpha)$. For the parasitoids, we sequenced two mitochondrial (cytochrome $b$ and 16S rDNA) and one nuclear (D2 region of the 28S rDNA) gene fragments (Table S2 in Supporting Information).

PCR for $C O I$ was performed in a total volume of $25 \mu \mathrm{L}$ containing $1 \mathrm{x}$ buffer, $3 \mathrm{mM}$ of $\mathrm{MgCl}_{2}$, $0.1 \mathrm{mM}$ of dNTPs, $0.5 \mu \mathrm{M}$ of each primer, 1 unit of Taq DNA (Promega, Madison, WI) and 1 $\mu \mathrm{L}$ of genomic DNA (Table S3 in Supporting Information). PCR for the other genes (i.e. EF1 $\alpha$, Hist3, cytb, 16S rDNA and 28S rDNA) followed the same general protocol as COI with the exception of $\mathrm{MgCl}_{2}$ concentration and PCR amplification conditions that differed between 
genes (Table S3 in Supporting Information). PCR fragments were sequenced directly in one direction at Macrogen (Korea) using BigDye Terminator v.3.1. The sequence data (homotomid COI, EF1 $\alpha$, Hist 3 and parasitoid cytb, 16S rDNA, 28S rDNA) sequences were deposited in GenBank under accession numbers KT273227-KT273238 and KU522537-KU522595 and aligned sequence are archived at http://doi.org/10.4225/35/57a95a900f19a.

\section{Phylogenetic analyses}

Sequences for each locus were aligned using the Muscle alignment tool in Geneious 6.1.7. Alignment of the protein-coding genes was checked by translating the sequences into amino acids using MEGA v 6.06 (Tamura et al., 2013). No evidence for the presence of pseudogenes (i.e. no stop codons or frameshifts) was detected. We used the nucleotide substitution model selected by JModelTest2 (Guindon \& Gascuel, 2003; Darriba et al., 2012), based on the Bayesian Information Criterion (BIC). When needed the shape parameter of the Gamma distribution $(\mathrm{G})$ and the proportion of invariant sites (I) were estimated in MEGA.

Sequence data of each gene were analysed using Maximum Likelihood (ML) in MEGA v 6.06. ML branch support was tested with 1,000 bootstrap pseudo-replicates. Nodes with bootstrap values $>70 \%$ were considered supported, and those with a value $>90 \%$ well-supported. Sequence data were also analysed using Bayesian Inference (BI) in MrBayes v 3.2.2 (Ronquist \& Huelsenbeck, 2003; Ronquist et al., 2012). Two runs of four Monte Carlo Markov Chain (MCMC) chains (3 "heated" and 1 "cold") were run in parallel in MrBayes for $2 \times 10^{6}$ generations and sampled every 5,000 generations. Tracer v1.6 (Drummond et al., 2012), as well as the standard deviation of split frequencies, were used to assess stationarity of the Markov chains.

\section{Species delimitation using COI for Mycopsylla and cytb for the parasitoids}


This method partitions the data into independent networks that link haplotypes using statistical parsimony based on a 95\% confidence interval (Templeton et al., 1992) and this can be seen as an initial step to visualize likely species boundaries. We used TCS v1.21 (Clement et al., 2000) and POPART (Leigh \& Bryant, 2015) to perform a statistical parsimony analysis on homotomid COI data and parasitoid cytb data.

The 'barcoding gap' is a discontinuity between pairwise mtDNA distances of conspecific and heterospecific individuals (Hebert et al., 2003; Čandek \& Kuntner, 2015) that often allows simple visual detection of species boundaries. We used the Kimura 2 parameter (K2P) distance model (Kimura, 1980) to calculate genetic distances in MEGA v 6.06. While the use of K2P has been questioned (Srivathsan \& Meier, 2012), it is widely adopted and facilitates comparison with other studies. TaxonDNA (Meier et al., 2006) was then used to cluster mtDNA sequences using the observed barcoding gap.

A GMYC model is a common statistical approach to single-locus species delimitation. It is based on the differentiation of branching rates resulting from a speciation process (Yule purebirth model) from those resulting from an intra-specific process (neutral coalescent model) (Pons et al., 2006). The number of species present in the dataset was determined using COI and cytb data with the single threshold method in the package 'splits' (Ezard et al., 2009) in R v3.1.0. This requires ultrametric trees, which were generated using Beast v1.8.0 (Drummond \& Rambaut, 2007; Drummond et al., 2012). Based on comparison of the Ln likelihood generated by DNAml and DNAmlk implemented in Phylip v3.6 (Felsenstein, 1989), a strict clock model was applied. A coalescent prior set to a constant population size was used, as it is thought to be 
more conservative than a Yule prior (Monaghan et al., 2009). All other priors for the model parameters were kept as default values. The MCMC chain was run in Beast for 10 million generations and sampled every 1000 generations. Tracer v1.6 was used to visualize the estimated sample size and stationarity of the parameters.

\section{RESULTS}

Adults Mycopsylla collected from F. macrophylla and F. rubiginosa grouped into two distinct morphospecies, as described in Hollis and Broomfield (1989) and Froggatt (Froggatt, 1901). Only nymphs of Mycopsylla were collected from F. watkinsiana. Parasitoids from all three Mycopsylla species were grouped into four morphotypes, although the delimitation was clearer for the males, due to variation in their antennal morphologies, than for the females (see parasitoid morphology section). Based on the identification keys they all appeared to belong to the genus Psyllaephagus (Riek, 1962; Noyes \& Hanson, 1996; Berry, 2007).

\section{Mycopsylla phylogenies}

After trimming of incomplete ends, 414 nucleotides of COI, 279 of EFI $\alpha$ and 285 of Hist 3 were kept for analysis. Across the 36 homotomid individuals used for COI, 16 haplotypes with 68 polymorphic sites were found. For EFl $\alpha$ and Hist3, 19 and 23 individuals were sequenced and we found 3 alleles with 2 polymorphic sites, and 2 alleles with only one polymorphic site, respectively.

JModelTest 2 indicated that the best models were HKY+I for COI, and JC for Hist 3 and EF1 $\alpha$. Mitochondrial ML and BI phylogenies showed the same topology (Fig. 2), with three highly supported clades (SI, SII, SIII). The nuclear genes were highly conserved, but the limited variation was congruent with the mtDNA clade structure. One fixed synonymous nucleotide substitution differentiated Hist 3 sequences of individuals collected on F. macrophylla from 
those collected on F. rubiginosa and F. watkinsiana. For EF1 $\alpha$, two nucleotide positions varied between clades. One synonymous substitution allowed differentiation of Mycopsylla collected from $F$. macrophylla from those collected from F. rubiginosa and F. watkinsiana, while another allowed differentiation of Mycopsylla collected from F. watkinsiana from those collected from F. macrophylla and F. rubiginosa (Fig. 2). Only two species of Mycopsylla have been described previously in Australia: M. fici from F. macrophylla and M. proxima from F. rubiginosa. No species has been previously described from $F$. watkinsiana and our data support a putative new Mycopsylla species (referred to as Mycopsylla sp.) on this host plant.

\section{Mycopsylla species delimitation using $C O I$ sequences}

\section{Statistical parsimony}

Eight steps (base differences), corresponding to the $95 \%$ cut-off, were set as the connection limit between haplotypes. We distinguished three independent networks for the COI data for Mycopsylla collected on F. macrophylla, F. rubiginosa and F. watkinsiana, respectively, with 16 haplotypes of which 10 were present with one individual only (Fig. S1 in Supporting Information).

\section{Barcoding gap}

Genetic differences between pairs of individuals varied from $0 \%$ to $12.6 \%$ for $C O I$. For COI the barcoding gap occurred between $2.2 \%$ (i.e. maximum intraspecific variation) and $5.8 \%$ (i.e. minimum interspecific divergence) (Fig. S2). It led to the delimitation of three species, i.e. $M$. fici, M. proxima and Mycopsylla sp. from F. watkinsiana (Table 1). Intraspecific divergences ranged from 5.8-6.5\% between Mycopsylla sp. and M. proxima to $11.4-12.6 \%$ between $M$. proxima and M. fici (Table 1).

GMYC 
The GMYC model that assigned individuals into five clusters was preferred over the null model of uniform branching rate, i.e. assuming one species (GMYC maximum likelihood=273.9, null model likelihood $=270.8, p=0.04$ ). The five clusters were 1) $M$. fici from the Australian mainland and New Zealand, 2) $M$. fici from $F$. macrophylla from LHI, 3) $M$. proxima from $F$. rubiginosa from Sydney, 4) M. proxima from F. rubiginosa from Northern NSW and 5) Mycopsylla sp. from F. watkinsiana.

In summary, two analyses (statistical parsimony and barcoding gap) using mtDNA sequences and nuclear sequences both recognized three homotomid species corresponding strictly to the three different fig species. However, GMYC further split: a) homotomids from F. macrophylla into mainland/New Zealand and LHI populations; and b) homotomids from F. rubiginosa into Sydney and northern NSW populations.

\section{Psyllaephagus phylogenies}

After trimming for incomplete ends 367, 190 and 290 nucleotides of the mitochondrial cytb and 16S rDNA, and nuclear 28S rDNA sequences, respectively, were kept for analysis. Across the 128 individuals tested, the $c y t b$ sequences displayed 147 polymorphic sites and 31 haplotypes were found. The 16S rDNA sequences had 71 polymorphic sites across 19 haplotypes for the 39 individuals sequenced. The 28S rDNA sequences displayed 37 polymorphic sites across seven alleles in the 33 individuals sequenced. $C y t b$ had the highest polymorphism $(\pi=0.17)$, followed by $16 \mathrm{~S}$ rDNA $(\pi=0.11)$ and the much less variable nuclear $28 \mathrm{~S}$ rDNA $(\pi=0.04)$.

JModelTest2 indicated that mitochondrial $c y t b$ and $16 \mathrm{~S}$ rDNA followed a HKY $+\mathrm{G}$ model, and the nuclear $28 \mathrm{~S}$ rDNA a $\mathrm{K} 80+\mathrm{G}$ model. ML and BI phylogenies showed the same topology for each gene. Although the phylogenies differed across the three genes, they did not conflict with each other in terms of clade membership, but represented different levels of resolution likely reflecting the difference in mutation rates of the genes used. When using nuclear $28 \mathrm{~S}$ rDNA to build the phylogeny, only four clades, each with high support, were observed (Fig. 3B). In 
contrast, $c y t b$ phylogenies split one $28 \mathrm{~S}$ rDNA clade into three highly supported sub-clades, PIV, PV and PVI (Fig. 3A); these clades were also supported by 16S rDNA presented in supporting information (Fig. S3). However, we observed some conflicts in terms of tree topology (Fig. 3), e.g. PII and PIII are sister clades when using 28S and 16S rDNA, but PII and PI are sister clades when using cytb. Individuals collected in New Zealand clustered with clade PIV, suggesting that clade PIV is P. cornwallensis.

\section{Psyllaephagus species delimitation using cytb sequences}

\section{Statistical parsimony}

Six independent networks were found using cytb sequences. Eight steps (base differences), corresponding to the $95 \%$ cut-off, were set as the connection limit between haplotypes. Only one network comprised a single haplotype, which grouped just five individuals (corresponding to PVI). The six networks corresponded to the same groups (PI, PII, PIII, PIV, PV, PVI) delineated with the phylogenetic tree (Fig. S4 in Supporting Information).

\section{Barcoding gap}

Genetic differences between pairs of individuals varied from $0 \%$ to $27.2 \%$ and the barcoding gap occurred between $1.7 \%$ (i.e. maximum intraspecific divergence) and $6.7 \%$ (i.e. minimum interspecific divergence). Using TaxonDNA and the previously found threshold percentages, six species were delimited (Fig. S2 in Supporting Information). Interspecific divergence of cytb ranged from 6.7-7.6\% between PV and PIV to 26.9-27.2\% between PI and PV (Table 1).

GMYC

The GMYC model that assigned individuals into six clusters was preferred over the null model of uniform branching rate (GMYC maximum likelihood $=719.9$, null model likelihood $=694.2$, $p<0.001)$. This means that all the clades delimited in the $c y t b$ tree constitute distinct species according to the GMYC method. 
$C y t b$ sequences suggested the existence of six parasitoid species, regardless of the delimitation method used. In contrast, when using $28 \mathrm{~S}$ rDNA sequences, only four groups were evident. Clades PIV, PV and PVI were grouped together, separately from clades PI, PII and PIII. Interestingly, Clade PVI grouped individuals collected on F. rubiginosa and $F$. watkinsiana on the mainland of Australia while clade PV contained individuals found on F. macrophylla on LHI. Clade PIV grouped individuals found on F. macrophylla on the mainland of Australia and in New Zealand. However, one individual collected on LHI was also found in this clade. Psyllaephagus sp. PI was a specialist of M. fici found on both the mainland and LHI, while PII and PIII were host generalists. We concluded that these six taxa are most likely all different species, varying in host specificity. Within species, there was no obvious geographic substructure.

\section{Parasitoid morphology}

All species had characteristics of the genus Psyllaephagus as described in Noyes \& Hanson (1996) and Berry (2007). Female body size differed significantly between some species (Kruskal-Wallis, $\chi^{2}=43.4, p=3.08 \mathrm{e}^{-8}$ ), with females of species PIV, PV and PVI being larger than those from species PI, PII and PIII (Fig. 4). The same was true for the ovipositor sheath to body length ratio, which was higher in PIV, PV and PVI than in PI, PII and PIII. In addition, PII had a higher ratio than PI and PIII, and PIV a higher ratio than PVI (Kruskal-Wallis, $\chi^{2}=60.9$, $p=7.8 \mathrm{e}^{-12}$ ). The shape of the antennal scape also differed between species; females of species PII, PIV, PV and PVI have an expanded scape while those from PI and PIII have a narrower, only slightly expanded scape (Fig. S5 in Supporting Information). Male body size also differed between species (Kruskal-Wallis, $\chi^{2}=27.3, p=5.06 \mathrm{e}^{-5}$ ), with species PIV bigger than species PI, PII and PIII (Fig. 4). Males of PV and PVI were not significantly different in size to males of the other species. The ratio of antenna to body length ratio did not differ between species in males or females. Male antennae also differed in form between some species (Fig. S5 in 
Supporting Information). Species PII, PIV, PV and PVI had filiform antennae without hairs, whereas species PI had filiform antennae but the flagellum was covered with hairs. Species PIII had flagellate antennae.

\section{Host-specificity of homotomids and parasitoids}

Each of the three Mycopsylla species appeared completely host-specific to one fig species (Fig. 2). Given this, we assumed that parasitoids collected from one Ficus species developed in the appropriate host-specific Mycopsylla species. Parasitoid species showed different levels of host specificity (Fig. 3), with three species (PI, PIV and PV) highly host specific to M. fici (on F. macrophylla), while the other three were polyphagous (PII attacked M. fici and M. proxima, PIII attacked all three Mycopsylla species, and PVI attacked M. proxima and Mycopsylla sp.) (Fig. 5). However, we were only able to sample a few individuals belonging to Mycopsylla sp. from F. watkinsiana and additional sampling may yield further information on its associated parasitoids (e.g. PII). In our sampling, only M. fici had host-specific associated parasitoids (Fig. $3)$.

\section{DISCUSSION}

We characterised three Mycopsylla species from three Ficus species by using genetic approaches and extensive field surveys of eight Ficus species in Australia and New Zealand. One of the three Mycopsylla species is a new undescribed species from $F$. watkinsiana. Furthermore, we characterised six parasitoid species of the genus Psyllaephagus, including five new species (Froggatt, 1901; Newman, 2004), that attack the Mycopsylla species. The three Mycopsylla species appeared highly host-specific, but host specificity patterns were more complex for Psyllaephagus, which included both specialists and generalists. Interestingly, only M. fici appeared to support specialist parasitoid species. 
The new Mycopsylla sp. on F. watkinsiana showed 5.8-6.5\% divergence in COI sequence from the closest species, M. proxima. Percy (2003) found that intraspecific mitochondrial divergence varied between 1 and $10 \%$ for psyllid species collected on different islands, but was restricted to an upper limit of 3\% for continental species. Taylor et al. (2016) identified a 5-6\% divergence as the threshold that best matched morphological and ecological characteristics for their triozid species delimitation. In addition, we found one fixed synonymous nucleotide difference between EFI $\alpha$ sequences between Mycopsylla sp. and M. proxima. Overall, these molecular data suggest a new Mycopsylla species, but as only nymphs were found, description of adult morphology was not possible.

Previously, only one Psyllaephagus species (P. cornwallensis, here Psyllaephagus sp. IV) associated with $M$. fici has been described and this was from New Zealand - outside the native range of its host (Berry, 2007). We also collected this species in Australia. Our molecular delimitation of parasitoid species supports the existence of at least four species using the slowevolving nuclear $28 \mathrm{~S}$ rDNA data, but more likely the six species suggested by using the faster evolving mitochondrial cytb data sequences (Lin \& Danforth, 2004). Other studies such as the ones on the pollinator wasp species on F. rubiginosa found a similar situation with additional species discovered based on cytb relative to $28 \mathrm{~S}$ sequences. However, the status of these additional species was then further supported by nuclear microsatellite markers (Haine et al., 2006, Darwell et al., 2014). Interestingly, while Psyllaephagus sp. PIV, PV, PVI, shared very similar features in terms of size, sheath length and antennal morphology, they were collected on two different land masses (PV/PIV) or from different hosts (PV-PIV/PVI). In addition, their mitochondrial sequences were at least $6 \%$ different. The lack of differentiation in nuclear DNA suggests relatively recent divergence, but it is possible that PIV and PV are strongly diverged populations of a single species, as observed for their host species $M$. fici. 
We found different levels of host-specificity across the fig Mycopsylla food web (Fig. 5). Here, we established that the herbivore species were highly host specific while their associated parasitoid species had various degrees of specialisation. Interestingly, host specificity reflects host availability; host tree species that occur at high densities are common and may therefore be a relatively stable resource for homotomids (and parasitoids) while trees with lower species abundance may be considered as a fluctuating resource for homotomids (and parasitoids).

Mycopsylla fici and M. proxima appeared highly host specific to F. macrophylla and $F$. rubiginosa, respectively. With only a few Mycopsylla individuals collected from $F$. watkinsiana, it is difficult to draw strong conclusions, but, given the high host specificity of $M$. fici and M. proxima, and the absence of homotomids from other Ficus species we surveyed, it seems likely that this putative new Mycopsylla sp. is specific to F. watkinsiana. Far more studies are available for insects from other families within Psylloidea and most of these described psyllids as highly host specific at the tree species level (Hodkinson, 2009; Burckhardt et al., 2014; Ouvrard et al., 2015). In addition, closely related psyllid species tend to develop on closely related plant species (Hollis \& Broomfield, 1989), as we found with Australian Mycopsylla species feeding only on Ficus species belonging to section Malvanthera.

The Psyllaephagus species detected in our study had different levels of host specificity. Three were highly host-specific to M. fici (two on the mainland and one on LHI), but none was specific to M. proxima or Mycopsylla sp. from $F$. watkinsiana. Generalist species attacked $M$. fici and M. proxima (PII) or all three Mycopsylla species (PIII). Nonetheless, more extensive sampling of Mycopsylla sp. may lead to the discovery of new parasitoid species that could be host-specific. The fact that only $M$. fici is currently known to have host-specific parasitoids may again reflect host availability, with high abundance of $M$. fici and much lower abundance for the other Mycopsylla species. This is consistent with the 'resource fragmentation hypothesis' 
(Janzen, 1981), which suggests that rare host species tend to not support specialist parasitoid species. Indeed, other studies have found that the number of specialist parasitoid species is positively correlated with host density (e.g. Dawah et al., 1995). Mycopsylla fici lerps are usually much bigger (up to 30 individuals in a lerp), and in higher abundance within and between trees (pers. obs.), than those of M. proxima (rarely more than two individuals per lerp). In addition, major outbreaks of homotomids have only been reported for M. fici.

Another interesting point is the absence of generalist parasitoids on LHI. This raises multiple questions regarding the host preferences and dispersal abilities of the generalist Psyllaephagus species. It could also indicate that Psyllaephagus PI, PIV and PV are better competitors than the other generalist species. When $M$. fici outbreaks occur, host resources may be abundant enough for all parasitoid species to coexist on this host. However, between outbreaks, populations of $M$. fici are far smaller and, extrinsic and intrinsic competition between parasitoid species may be intense (Harvey et al., 2013) and favour the stronger competitors (see for instance Patil et al., 1994; Feng et al., 2015). On the mainland, other Mycopsylla species may provide refuges for populations of the weaker competitors amongst generalist parasitoid species. However, they lack alternative hosts on LHI so may be driven to extinction by specialists when hosts are rare and competition is intense (Paranhos et al., 2013).

One important aspect that we were unable to investigate here is whether some of the parasitoid species are hyperparasitoids. Hyperparasitoids appear common in systems where the primary 447 hosts are hemipteran (e.g. in aphids - Muller et al., 1999) and this will be an interesting topic for 448 further investigation. It could also explain the restriction of some species (e.g. PII or PIII) to the mainland if they attack parasitoid species also present only on the mainland.

Our study focused primarily on establishing the number of species of homotomids and parasitoids and patterns of host specificity. However, our sequence data also provided some 
interesting preliminary phylogeographic insights. Mycopsylla fici clustered into two wellsupported clades on the Australian mainland/New Zealand and on LHI, suggesting that the LHI population may be genetically discrete. While within-species phylogeographic patterns were recovered for $M$. fici, among-species phylogeographic patterns can be discussed for the parasitoid species. Interestingly, the genetically close and morphologically similar parasitoids PIV and PV, both host specific to M. fici, show different distribution patterns, with PIV mainly on the mainland and PV only recorded on LHI. On the other hand, PI, also host specific to $M$. fici, was collected repeatedly on both mainland and LHI. This may suggest more recent or ongoing exchange of some parasitoid species between LHI and the mainland without any mixing of M. fici. Surprisingly, only one individual from LHI was found in clade PIV. This could indicate occasional dispersal between island and mainland. These observations are interesting as they imply that different parasitoid species attacking the same host may have different dispersal abilities. These preliminary observations should be followed up with targeted population genetic studies of focal species within this system.

\section{Conclusions}

In this study, our data support a putative new species of Mycopsylla homotomids and five new species of Psyllaephagus parasitoids associated with Ficus species in Australia. Revealing unrecognised species diversity is a crucial step towards understanding species interactions and food webs, and may be of particular importance for parasitoids, for which diversity is often underestimated due to the existence of numerous cryptic species. In addition, sampling a hostparasitoid system across the geographic range of the host plant can provide insights into the different phylogeographic patterns of interacting species, their relative dispersal abilities and how geographic barriers may impact species in various ways.

\section{ACKNOWLEDGMENTS}


480 CF was supported by a Hawkesbury Institute for the Environment Postgraduate Research 481 Award. This research was also supported by a research grant from the Hermon Slade 482 Foundation (HSF 12/10) to MR and JMC. We particularly thank John Early for his help with 483 New Zealand collections. We thank Tim Sutton, Desi Quintans, Aidan Hall and Courtney 484 Campany for helping with field collections as well as the Lord Howe Island Board and NSW 485 Office of Environment and Heritage for permission to conduct research and logistical support. 486 We also thank three anonymous reviewers for their valuable comments that improved an earlier 487 version of the manuscript. 
Bain, J. (2004) New records. Forest Health News, 142, 1-2.

Basset, Y. \& Novotny, V. (1999) Species richness of insect herbivore communities on Ficus in Papua New Guinea. Biological Journal of the Linnean Society, 67, 477-499.

Basset, Y., Novotny, V. \& Weiblen, G.D. (1997) Ficus: a ressource for arthropods in the tropics, with particular reference to New Guinea. In Forests and insects (ed. by Watt, A.D., Stork, N.E. \& Hunter, M.D.), pp. 341-361. Chapman and Hall, London, UK.

Benjamini, Y. \& Hochberg, Y. (1995) Controlling the false discovery rate: a practical and powerful approach to multiple testing. Journal of the Royal Statistical Society. Series B (Methodological), 57, 289-300.

Berry, J.A. (2007) Key to the New Zealand species of Psyllaephagus Ashmead (Hymenoptera: Encyrtidae) with descriptions of three new species and a new record of the psyllid hyperparasitoid Coccidoctonus psyllae Riek (Hymenoptera: Encyrtidae). Australian Journal of Entomology, 46, 99-105.

Buckman, R.S., Mound, L.A. \& Whiting, M.F. (2013) Phylogeny of thrips (Insecta: Thysanoptera) based on five molecular loci. Systematic Entomology, 38, 123-133.

Burckhardt, D., Ouvrard, D., Queiroz, D. \& Percy, D. (2014) Psyllid host-plants (Hemiptera: Psylloidea): resolving a semantic problem. Florida Entomologist, 97, 242-246.

Campbell, B., Heraty, J., Rasplus, J.-Y., Chan, K., Steffen-Campbell, J. \& Babcock, C. (2000) Molecular Systematics of the Chalcidoidea using 28S-D2 rDNA. In Hymenoptera: Evolution, Biodoversity and Biological Control (ed. by Andrew, A. \& Dowton, M.), pp. 59-73.CSIRO Publishing.

Čandek, K. \& Kuntner, M. (2015) DNA barcoding gap: reliable species identification over morphological and geographical scales. Molecular Ecology Resources, 5, 268-277.

Clement, M., Posada, D. \& Crandall, K.A. (2000) TCS: a computer program to estimate gene genealogies. Molecular Ecology, 9, 1657-9.

Cruaud, A., Rønsted, N., Chantarasuwan, B., Chou, L.S., Clement, W.L., Couloux, A., Cousins, B., Genson, G., Harrison, R.D., Hanson, P.E., Hossaert-McKey, M., Jabbour-Zahab, R., Jousselin, E., Kerdelhué, C., Kjellberg, F., Lopez-Vaamonde, C., Peebles, J., Peng, Y.-Q., Pereira, R.A.S., Schramm, T., Ubaidillah, R., van Noort, S., Weiblen, G.D., Yang, D.-R., Yodpinyanee, A., Libeskind-Hadas, Cook, J.M., Rasplus, J.-Y. \& Savolainen, V. (2012) An extreme case of plant-insect codiversification: figs and fig-pollinating wasps. Systematic Biology, 61, 1029-47.

Darriba, D., Taboada, G.L., Doallo, R. \& Posada, D. (2012) jModelTest 2: more models, new heuristics and parallel computing. Nature methods, $9,772$.

Darwell, C.T., Al-Beidh, S. \& Cook, J.M. (2014) Molecular species delimitation of a symbiotic fig-pollinating wasp species complex reveals extreme deviation from reciprocal partner specificity. BMC Evolutionary Biology, 14, 189.

Dawah, H.A., Hawkins, B.A. \& Claridge, M.F. (1995) Structure of the parasitoid communities of grass-feeding chalcid wasps. Journal of Animal Ecology, 64, 708-720. 
De Mendiburu, F. (2014) Agricolae: Statistical procedures for agricultural research.

530 Dixon, D.J. (2001) Figs, wasps and species concepts: a re-evaluation of the infraspecific taxa of 531 Ficus macrophylla (Moraceae: Urostigma sect. Malvanthera). Australian Systematic Botany, 14, 125-132.

Drummond, A.J. \& Rambaut, A. (2007) BEAST: Bayesian evolutionary analysis by sampling trees. BMC Evolutionary Biology, 7, 214.

Drummond, A.J., Suchard, M.A., Xie, D. \& Rambaut, A. (2012) Bayesian phylogenetics with BEAUti and the BEAST 1.7. Molecular Biology and Evolution, 29, 1969-73.

Ezard, T., Fujisawa, T. \& Barraclough, T. (2009) "Splits: SPecies' LImits by Threshold Statistics, R package version 1.0-11/r29.

Felsenstein, J. (1989) PHYLIP - Phylogeny Inference Package (Version 3.2). Cladistics, 5, 164 540166.

541 Feng, Y., Wratten, S., Sandhu, H. \& Keller, M. (2015) Interspecific competition between two 542 generalist parasitoids that attack the leafroller Epiphyas postvittana (Lepidoptera: Tortricidae).

543 Bulletin of Entomological Research, 105, 426-433.

544 Frodin, D.G. (2004) History and concepts of big plant genera. Taxon, 53, 753-776.

Froggatt, W.W. (1901) Australian Psyllidae. Part II. Proceedings of the Linnean Society of New 546 South Wales, 26, 242-298.

547 Gherlenda, A.N., Esveld, J.L., Hall, A.A.G. \& Duursma, R.A. (2016) Boom and bust : rapid 548 feedback responses between insect outbreak dynamics and canopy leaf area impacted by rainfall 549 and $\mathrm{CO}_{2}$. Global Change Biology, in press

550 Guindon, S. \& Gascuel, O. (2003) A simple, fast, and accurate algorithm to estimate large 551 phylogenies by maximum likelihood. Systematic Biology, 52, 696-704.

Haine, E.R., Martin, J. \& Cook, J.M. (2006) Deep mtDNA divergences indicate cryptic species in a fig-pollinating wasp. BMC Evolutionary Biology, 6, 83-94.

Hall, A.A.G., Gherlenda, A.N., Hasegawa, S., Johnson, S.N., Cook, J.M. \& Riegler, M. (2015) Anatomy of an outbreak: the biology and population dynamics of a Cardiaspina psyllid species in an endangered woodland ecosystem. Agricultural and Forest Entomology, 17, 292-301.

Hall, A.A.G., Morrow, J.L., Fromont, C., Steinbauer, M.J., Taylor, G.S., Johnson, S.N., Cook, J.M. \& Riegler, M. (2016) Codivergence of the primary bacterial endosymbiont of psyllids versus host switches and replacement of their secondary bacterial endosymbionts. Environmental Microbiology, in press.

Harvey, J.A., Poelman, E.H. \& Tanaka, T. (2013) Intrinsic inter- and intraspecific competition in parasitoid wasps. Annual Review of Entomology, 58, 333-351 through DNA barcodes. Proceedings of the Royal Society B: Biological Sciences, 270, 313-21. outbreak of 1938 in Nebraska. Journal of the Kansas Entomological Society, 20, 88-92.

Hodkinson, I.D. (2009) Life cycle variation and adaptation in jumping plant lice (Insecta: 
Hollis, D. \& Broomfield, P.S. (1989) Ficus-feeding psyllids (Homoptera), with special reference to the Homotomidae. Bulletin of The British Museum (Natural History) Entomology, 58, 131183.

Janzen, D.H. (1979) How to be a Fig. Annual Review of Ecology and Systematics, 10, 13-51.

Janzen, D.H. (1981) The peak in North American ichneumonid species richness lies between $57438^{\circ}$ and $42^{\circ}$ N. Ecology, 62, 532-537.

Jermiin, L.S. \& Crozier, R.H. (1994) The cytochrome b region in the mitochondrial DNA of the ant Tetraponera rufoniger: sequence divergence in Hymenoptera may be associated with nucleotide content. Journal of Molecular Evolution, 38, 282-294.

Kimura, M. (1980) A simple method for estimating evolutionary rate of base substitutions through comparative studies of nucleotide sequences. Journal of Molecular Evolution, 16, 111120.

LaSalle, J. (1994) North American genera of Tetrastichinae (Hymenoptera: Eulophidae). Journal of Natural History, 28, 109-236.

Leigh, J.W. \& Bryant, D. (2015) POPART: full-feature software for haplotype network construction. Methods in Ecology and Evolution, 6, 1110-1116.

Lin, C.-P. \& Danforth, B.N. (2004) How do insect nuclear and mitochondrial gene substitution patterns differ? Insights from Bayesian analyses of combined datasets. Molecular Phylogenetics and Evolution, 30, 686-702.

Liu, D., Trumble, J.T. \& Stouthamer, R. (2006) Genetic differentiation between eastern populations and recent introductions of potato psyllid (Bactericera cockerelli) into western North America. Entomologia Experimentalis et Applicata, 118, 177-183.

Meier, R., Shiyang, K., Vaidya, G. \& Ng, P.K.L. (2006) DNA barcoding and taxonomy in Diptera: a tale of high intraspecific variability and low identification success. Systematic Biology, 55, 715-28.

Monaghan, M.T., Wild, R., Elliot, M., Fujisawa, T., Balke, M., Inward, D.J.G., Lees, D.C., Ranaivosolo, R., Eggleton, P., Barraclough, T.G. \& Vogler, A.P. (2009) Accelerated species inventory on Madagascar using coalescent-based models of species delineation. Systematic Biology, 58, 298-311.

Mora, C., Tittensor, D.P., Adl, S., Simpson, A.G.B. \& Worm, B. (2011) How many species are there on Earth and in the ocean? PLoS Biology, 9, e1001127.

600 Muller, C.B., Adriaanse, I.C.T., Belshaw, R. \& Godfray, H.C.J. (1999) The structure of an 601 aphid-parasitoid community. Journal of Animal Ecology, 68, 346-370.

Newman, A.K.L. (2004) The biology of Mycopsylla fici Tryon on its sole host, Ficus 603 macrophylla Desf. ex Pers. Unpublished PhD Thesis. Macquarie University, Sydney. in Papua New Guinea. Journal of Biogeography, 32, 1303-1314. 
Noyes, J.S. \& Hanson, P. (1996) Encyrtidae (Hymenoptera: Chalcidoidea) of Costa Rica: the genera and species associated with jumping plant-lice (Homoptera: Psylloidea). BulletinNatural History Museum Entomology Series, 65, 105-164.

Ouvrard, D., Chalise, P. \& Percy, D.M. (2015) Host-plant leaps versus host-plant shuffle: a global survey reveals contrasting patterns in an oligophagous insect group (Hemiptera, Psylloidea). Systematics and Biodiversity, 13, 434-454.

Paranhos, B.J., Sivinski, J., Stuhl, C., Holler, T. \& Aluja, M. (2013) Intrinsic competition and competitor-free-space influence the coexistence of parasitoids (Hymenoptera : Braconidae : Opiinae) of Neotropical Tephritidae (Diptera). Environmental Entomology, 42, 717-723.

Patil, N.G., Baker, P.S., Groot, W. \& Waage, J.K. (1994) Competition between Psyllaephagus yaseeni and Tamarixia leucaenae two parasitoids of the leucaena psyllid (Heteropsylla cubana). International Journal of Pest Management, 40, 211-215.

Percy, D.M. (2003) Radiation, diversity, and host-plant interactions among island and continental legume-feeding psyllids. Evolution, 57(11), 2540-2556.

Pimm, S.L., Lawton, J.H. \& Cohen, J.E. (1991) Food web patterns and their consequences. Nature, 350, 669-674.

Pons, J., Barraclough, T.G., Gomez-Zurita, J., Cardoso, A., Duran, D.P., Hazell, S., Kamoun, S., Sumlin, W.D. \& Vogler, A.P. (2006) Sequence-based species delimitation for the DNA taxonomy of undescribed insects. Systematic Biology, 55, 595-609.

R Development Core Team (2014) R: A language and environment for statistical computing. R Foundation for Statistical Computing, Vienna.

Riek, E.F. (1962) The Australian species of Psyllaephagus (Hymenoptera: Encyrtidae), parasites of psyllids (Homoptera). Australian Journal of Zoology, 10, 684-757.

Ronquist, F. \& Huelsenbeck, J.P. (2003) MrBayes 3: Bayesian phylogenetic inference under mixed models. Bioinformatics, 19, 1572-1574.

Ronquist, F., Teslenko, M., Mark, P. van der, Ayres, D.L., Darling, A., Höhna, S., Larget, B., Liu, L., Suchard, M.A. \& Huelsenbeck, J.P. (2012) MrBayes 3.2: efficient Bayesian phylogenetic inference and model choice across a large model space. Systematic Biology, 61, $539-42$.

Rønsted, N., Weiblen, G.D., Clement, W.L., Zerega, N.J.C. \& Savolainen, V. (2008) Reconstructing the phylogeny of figs (Ficus, Moraceae) to reveal the history of the fig pollination mutualism. Symbiosis, 45, 45-55.

Schulmeister, S. (2003) Simultaneous analysis of basal Hymenoptera (Insecta): Introducing robust-choice sensitivity analysis. Biological Journal of the Linnean Society, 79, 245-275.

Srivathsan, A. \& Meier, R. (2012) On the inappropriate use of Kimura-2-parameter (K2P) divergences in the DNA-barcoding literature. Cladistics, 28, 190-194.

Stiling, P. \& Cornelissen, T. (2005) What makes a successful biocontrol agent? A meta-analysis of biological control agent performance. Biological Control, 34, 236-246.

Tamura, K., Stecher, G., Peterson, D., Filipski, A. \& Kumar, S. (2013) MEGA6: Molecular Evolutionary Genetics Analysis version 6.0. Molecular Biology and Evolution, 30, 2725-2729. 
648 Taylor, G.S., Fagan-Jeffries, E.P. \& Austin, A.D. (2016) A new genus and twenty new species 649 of Australian jumping plant-lice (Psylloidea: Triozidae) from Eremophila and Myoporum 650 (Scrophulariaceae: Myoporeae). Zootaxa, 4073, 1-84.

651 Templeton, A.R., Crandall, K.A. \& Sing, C.F. (1992) A cladistic analysis of phenotypic 652 associations with haplotypes inferred from restriction endonuclease mapping and DNA 653 sequence data. III. Cladogram estimation. Genetics, 132, 619-633.

654 Terborgh, J. (1986) Keystone plant resources in the tropical forest. In Conservation Biology, the 655 Science of Scarcity and Diversity (ed. by Soule, M.E.), pp. 330-344. Sinaucr, Sunderland, MA.

656 Veen, F.F.J. van, Morris, R.J. \& Godfray, H.C.J. (2006) Apparent competition, quantitative 657 food webs, and the structure of phytophagous insect communities. Annual Review of 658 Entomology, 51, 187-208.

659 Walsh, P.S., Metzger, D.A. \& Higuchi, R. (1991) Chelex 100 as a medium for simple extraction 660 of DNA for PCR-based typing from forensic material. BioTechniques, 10, 506-513.

661 
667

\begin{tabular}{lcccc}
\hline A) & M. fici_mainland & M.fici_LHI & Mycospylla $\mathrm{sp}$. & M. proxima \\
\hline M. fici_mainland & $\mathbf{1 . 2}$ & & & \\
M.fici_LHI & $\mathbf{1 . 5 - 2 . 2}$ & $\mathbf{0}$ & & \\
Mycospylla sp. & $9.9-10.7$ & $10.2-10.4$ & $\mathbf{0 . 2}$ & \\
M. proxima & $11.4-12.6$ & $11.6-12.1$ & $5.8-6.5$ & $\mathbf{0 . 2}-\mathbf{1 . 2}$ \\
\hline
\end{tabular}

\begin{tabular}{lcccccc}
\hline B) & PI & PII & PIII & PIV & PV & PVI \\
\hline PI & $\mathbf{0}$ & & & & & \\
PII & $22.7-23$ & $\mathbf{0 . 6}$ & & & & \\
PIII & $21.8-23.2$ & $21.6-22.1$ & $\mathbf{1 . 7}$ & & & \\
PIV & $24.4-24.6$ & $22.7-23.5$ & $22.1-23.5$ & $\mathbf{0 . 8}$ & & \\
PV & $26.9-27.2$ & $22.7-23.2$ & $21.8-23.2$ & $6.7-7.6$ & $\mathbf{0 . 3}$ & \\
PVI & 26.1 & $23.8-24.1$ & $22.4-23.2$ & $11.2-11.8$ & $12.9-13.2$ & $\mathbf{0}$ \\
\hline
\end{tabular}
are the minimal and maximal values of pairwise divergences between species total of 414 and 357 bases for the homotomid COI and parasitoid $c y t b$, respectively. In bold, intra-specific divergence. The percentages presented in the table 
Figure 1: Maps of the Mycopsylla and Psyllaephagus collections in Australia and New Zealand. Both Mycopsylla and Psyllaephagus were collected in LHI (light green square) and Auckland (black diamond) while only Mycopsylla were collected in Melbourne (yellow circle). Maps A) and B) represent the collections of Mycopsylla (circle) and Psyllaephagus (square), respectively, made in Australia. Colours correspond to the tree species from which collections were made (blue from $F$. macrophylla, green from $F$. rubiginosa and red from $F$. watkinsiana). The intensity of the colours corresponds to the sampling effort - the darker the colour, the higher the number of insects collected. On the left side, the yellow to red scale corresponds to the colour used for the phylogenetic trees. Brunswick H. is Brunswick Heads and Coffs H. is Coffs Harbour. Scales are in $\mathrm{km}$.

Figure 2: 50\% majority rule consensus tree constructed using BI of Mycopsylla COI sequences. The colour of the tip name corresponds to the host tree of collected Mycopsylla, blue: $F$. macrophylla, green: F. rubiginosa and red: F. watkinsiana. The colour of the circle in front of the tip name corresponds to the location where the homotomid was collected. The gradient $\mathrm{S} / \mathrm{N}$ on the mainland of Australia is represented by a gradient from yellow to red, LHI individuals are represented by light green squares and Auckland individuals by black diamonds. Black triangles and circles indicate a nucleotide change between EFI $\alpha$ and Hist 3 sequences, respectively, of the three species. Topologies of ML and BI were identical. Numbers at the nodes are posterior probabilities from BI analysis (lower number) and ML bootstrap values (upper number), estimated from 1000 bootstrap replicates. Scale represents the number of substitutions per site.

Figure 3: 50\% majority rule consensus tree constructed using BI of A) cytb sequences and B) 28S rDNA for Psyllaephagus. The colour of the tip name corresponds to the host tree of collected Psyllaephagus, blue: F. macrophylla, green: F. rubiginosa and red: F. watkinsiana. The colour of the circle in front of the tip name corresponds to the location where the parasitoid was collected. The gradient $\mathrm{S} / \mathrm{N}$ on the mainland of Australia is represented by a gradient from yellow to red, LHI individuals are represented by light green squares and Auckland individuals by black diamonds. PIV is $P$. cornwallensis. Topologies of ML and BI were identical. Numbers at the nodes are posterior probabilities from BI analysis (lower number) and ML bootstrap values (upper number), estimated from 1000 bootstrap replicates. Scale represents the number of substitutions per site.

Figure 4: Comparison of the length of body (A) and ratio ovipositor sheath/body length (B) of female and size of body (C) of male of different Psyllaephagus species. The letters correspond to the result of the post-hoc test: species with the same letter are not statistically different.

Figure 5: Food web of the Mycopsylla homotomids and their associated Psyllaephagus parasitoids found on three species of fig trees. The lower level corresponds to the tree species the insects were collected from. The second level corresponds to the Mycopsylla spp. collected, $M$. fici collected on the mainland of Australia and on LHI are separate as they have different parasitoid species attacking them. The third level corresponds to Psyllaephagus that emerged from the different Mycopsylla spp. The boxes are coloured according to the specialisation of the insect species: light grey for specialists and dark grey for generalists. 


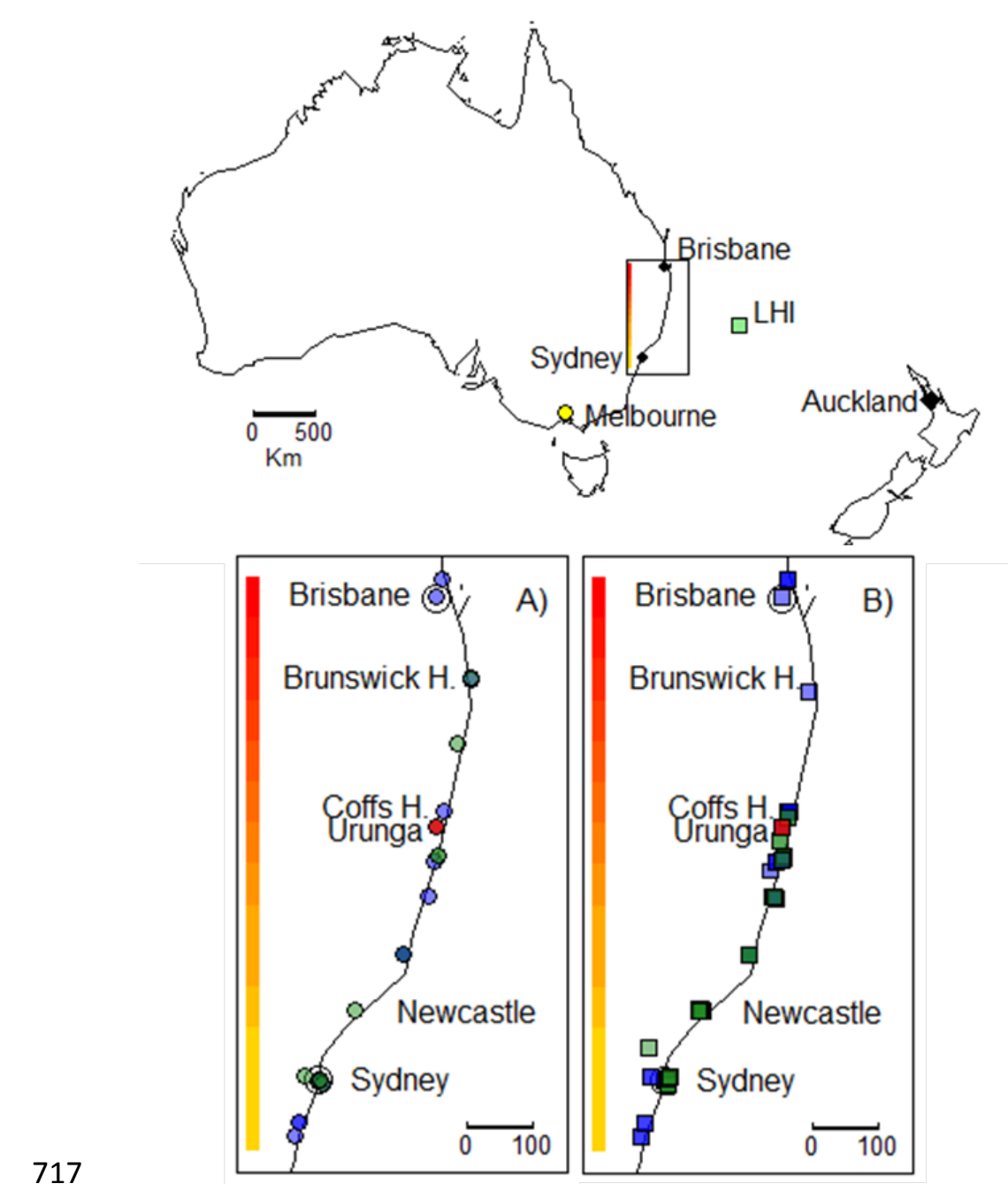

718 Fig. 1 


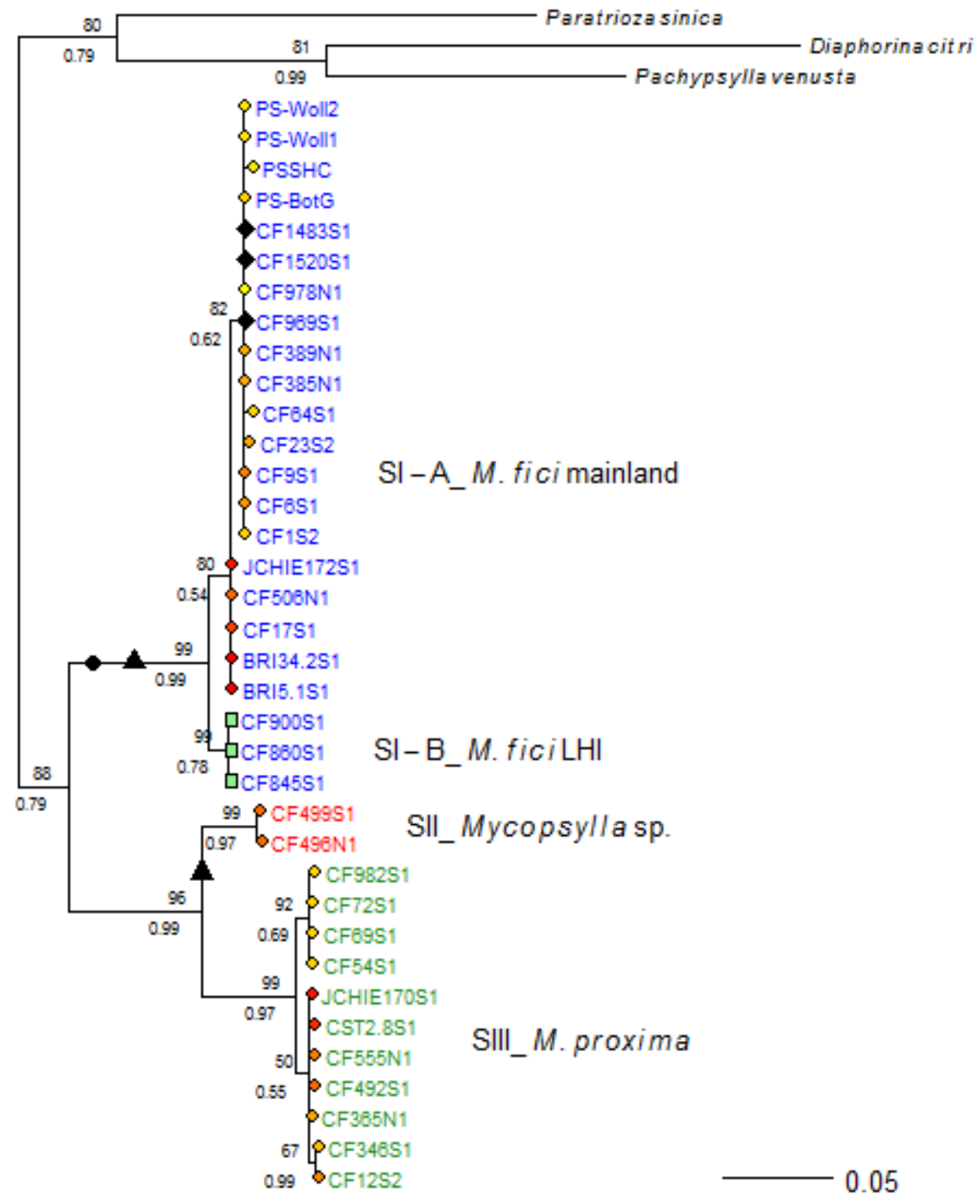

720

721

722 Fig. 2 


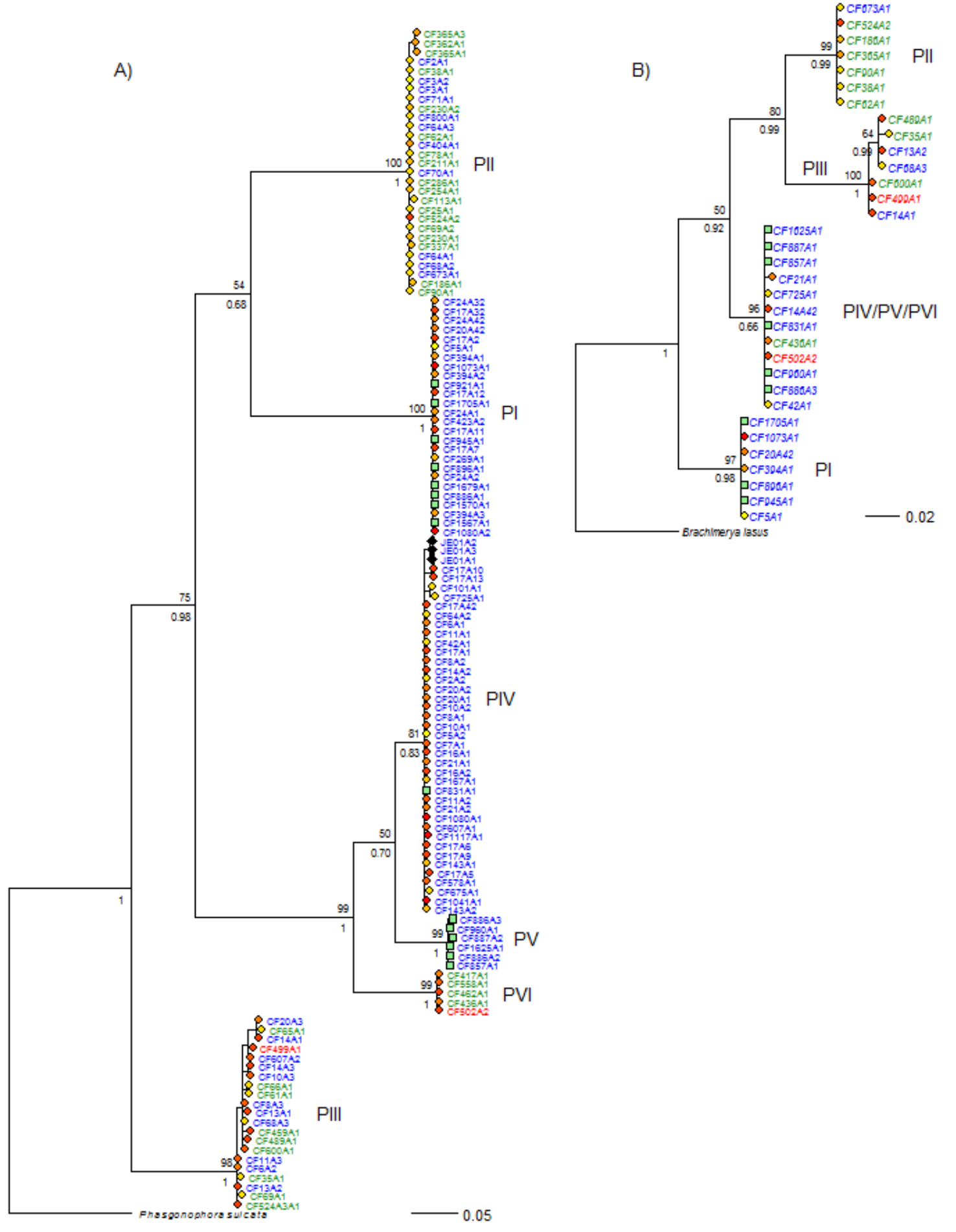

724

725

Fig. 3

726 

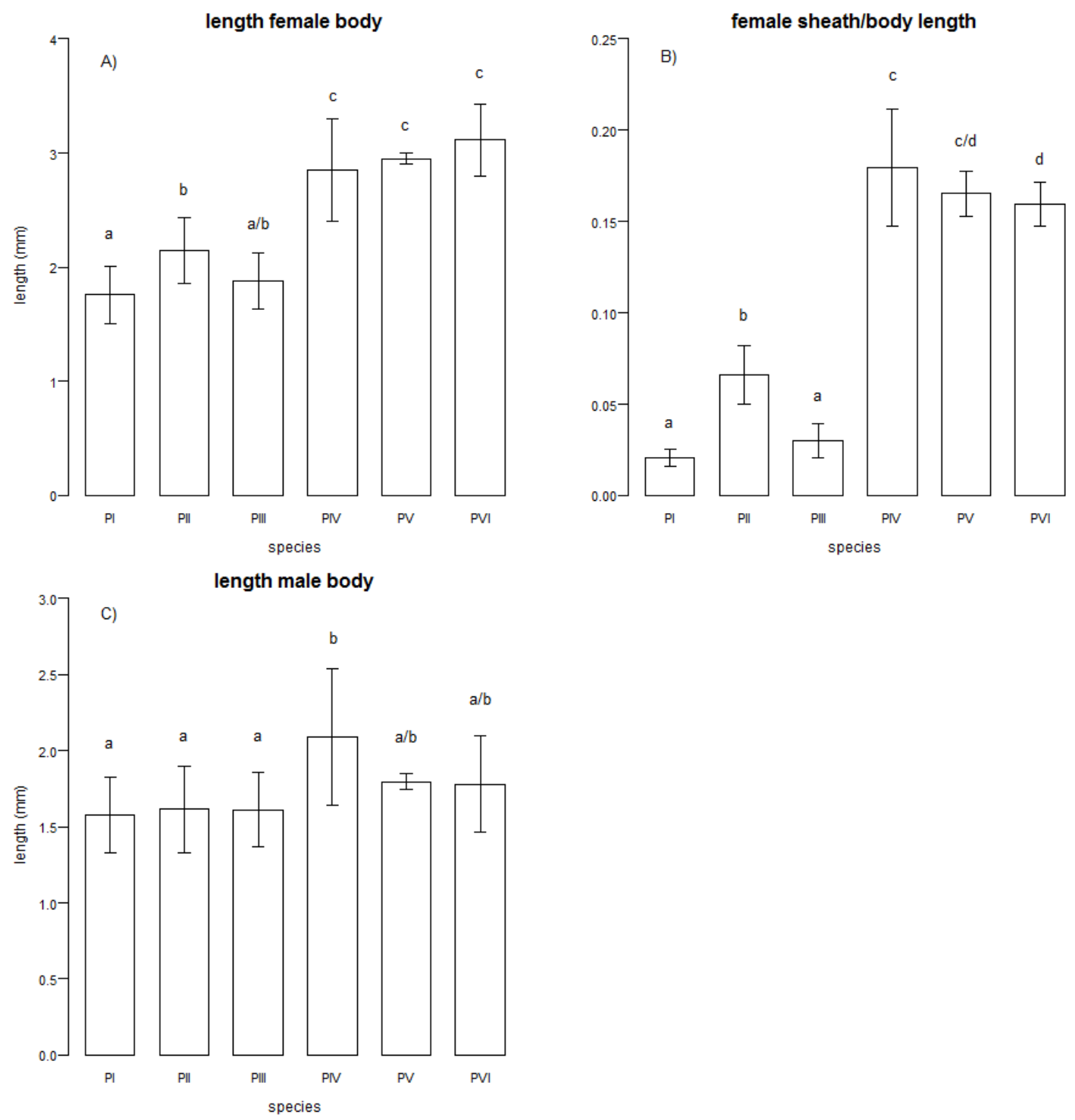

727

728

729

Fig. 4

730 


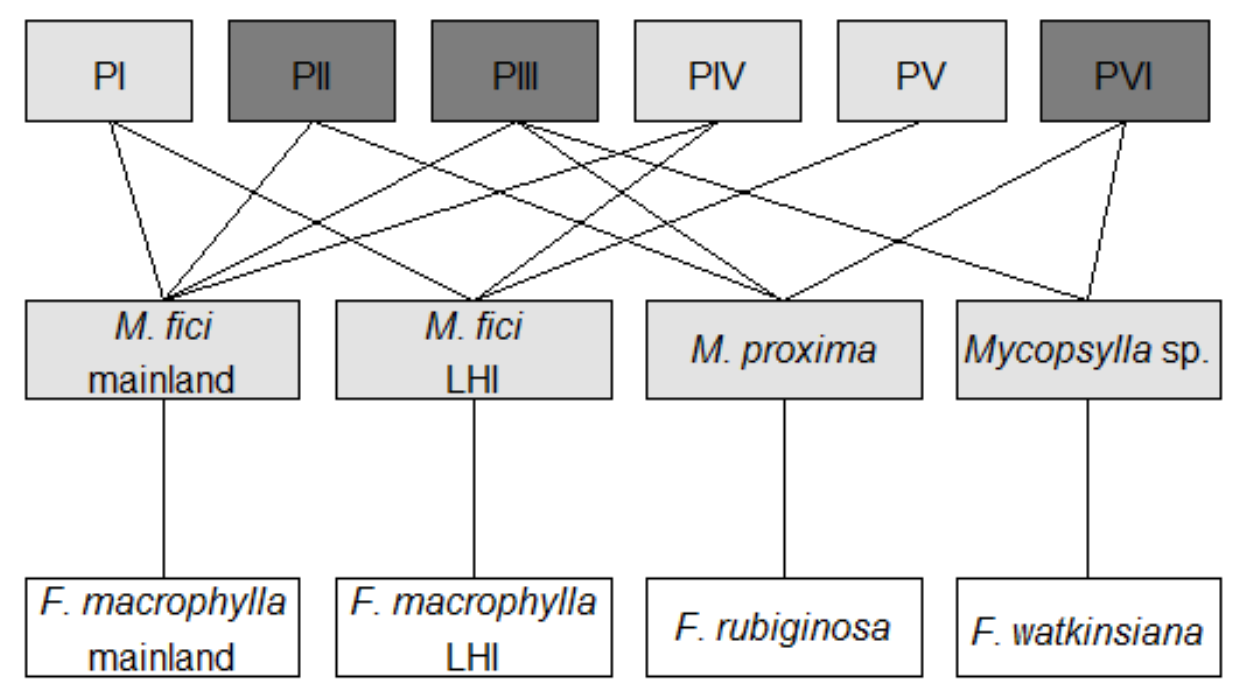

Fig. 5 